\title{
Paradigm of the student-teacher relationship in the modern educational environment
}

\author{
Irina $\mathrm{N}$. Dobrotina ${ }^{1, *}$ and Elena L. Erokhina ${ }^{2}$ \\ ${ }^{1}$ ISED RAE, Center of Philological Education, 105062, Moscow, Russia \\ ${ }^{2} \mathrm{MSU}$, Philological Department, Moscow, Russia
}

\begin{abstract}
The authors of the article claim that the information age makes it crucial to reconsider the principles of the student-teacher relationship (teacher communication style). Traditionally the interaction of subjects of educational discourse in the pedagogical rhetoric is considered from the standpoint of communicative leadership of the teacher. The information age is changing the meaning of term "communicative leader", which is described in this article with examples of interaction between research education subjects. The new communicative leadership supposes a three-level model of a teacher's communicative competences: conscious rhetoric skills (the ability to manage creative interaction with students) and facilitation skills. Further in the article, the comparison of facilitative and conventional teacher communication styles is carried out. Facilitation is opposed to inefficient communication styles and is seen as different from efficient communication styles in the level of trust and respect for the student, as reflected in the provision of freedom of choice and independence in problem solving processes. The facilitative student-teacher relationship principle in the educational environment is demonstrated based on the example of grammar school No. 118 in Rostov-on-Don. It is stated in the article that case technology can be considered to be one of the efficient student-teacher interaction technologies corresponding to facilitation ideas. The teacher's operating model for building this case is described.
\end{abstract}

New opportunities in the educational process are driving the need for a thorough understanding of such terms as "information-learning space" and "educational milieu". The information environment of society is inextricably connected with the educational space for pupils and higher education students. That is why pedagogical research now often uses the term "information-learning space", defined as an "environment of verbal and documental-type communication, formed for the purposes of cultural and educational development of its subjects". [1] The modern educational space is characterised by a massive amount of information, a complex socialized knowledge system, and a variety of ways of accessing knowledge and cultural values.

Today's senior high school students should know how to work under the constantly increasing amount and speed of information flows, modernisation of the social communication infrastructure, and the growth of digital information. Along with educational resources for compulsory education, we are experiencing an emergence of resources that are giving students the opportunity to receive additional education and satisfy self-education needs (e-libraries, virtual museums, exhibitions, audio and video materials, etc.). The accessibility of educational space removes space constraints, thereby enabling a student to access any kind of information, regardless of space and time.

Researchers note that increases in information volume and knowledge volume are fully independent processes and are not directly proportional. Information does not become knowledge automatically; one must navigate among various information flows in order to learn how to transform information into knowledge. It is important for students to feel confident in this environment and how to manage it so that they have no difficulties in further learning in order to expand their professional growth opportunities.

The information age, being characterised by intensive knowledge augmentation, makes it necessary to reconsider psycho-pedagogical approaches to the processes of receiving information and learning activity management and, consequently, the principles of the student-teacher relationship.

Research in effective verbal interaction between educational process subjects has a strong theoretical base in Russian pedagogical science. Research on pedagogical rhetoric shows the main models of "studentteacher" interaction as teacher's verbal behaviour styles - "individual-typological peculiarities of teacher-learner psycho-social interaction” [2].

\footnotetext{
Corresponding author: dobrotina.irina@yandex.ru
} 
N.F. Maslova, T.A. Ladyzhenskaya, N.A. Kurduykova, and others single out two main verbal behaviour styles of teachers: "democratic" and "authoritarian", opposed by the level of individualisation of the addressee in communication. This classification is specified by V. A. Kan-Kalik, who identifies five pedagogical communication styles: communication based on enthusiasm for joint activities, friendly disposition, communication-distance, communicationintimidation, and communication-pandering.

It should be noted that the interaction of educational discourse subjects is traditionally viewed from the position of a teacher's communicative leadership. One of the founders of pedagogical rhetoric, A. K. Mikhalskaya, claims that the main task of pedagogical rhetoric is "researching a teacher's verbal behaviour as a management and control tool for speech communication of participants in a speech situation." [3]

This statement is fair for the communicative environment of "traditional" education, where the leading role of a teacher is unquestionable and the teacher is the carrier of absolute knowledge in terms of the subject, knowledge on modes of operation, criteria for evaluating results, as well as possession of the unconditional right to initiate communication and influence its members, processes, and results.

Currently, the idea of inquiry-based learning is becoming more and more popular. This type of learning is based not only on independent obtainment, selection, analysis and systematization of information, but also on showing initiative in obtaining new knowledge (an instinct to explore). The tasks of this learning style are: to form a student's need to actualise their cognitive activity and to understand the meaning of inquiry-based learning in real life for purposes of efficient activity in any professional sphere, for self-development, and for self-improvement.

What style of pedagogical communication in an inquiry-based learning environment is best (based on A.A. Leontiev's work, we define the best pedagogical communication as the "style of the teacher's communication... with learners during the teaching and learning process that creates the best conditions for a learner's motivation and creative learning activity and allows a teacher to engage their personality peculiarities in the teaching and learning process")? [4].

The organization of training process in the research teaching presupposes the expansion of space-time framework of the traditional school lessons. A special communicative space is created, including such a complex speech event as the research process and its results. The communicants' roles are changed, and the teacher takes on the role of a research advisor.

We see the communicative competence model of the teacher - research advisor as a three-level system [5]. The first basic level is the conscious use of rhetorical tools, which, according to A. A. Mineeva's definition, represent the "reconsideration of learning process management as a proper dialogue communication that corresponds to rhetorical canons." [6]

Training dialogue is a basic condition for the best pedagogical communication in inquiry-based learning.
The second, central level of the system is a teacher's professional competence in managing creative interaction. The development of rhetoric provision principles, conditions, and methods for this interaction were introduced by A. A. Murashov, who said that "creative interaction didactics overcome communication barriers that exist in classroom communication with the help of its non-traditional forms and functional pedagogical tasks, as well as the creativity oriented elements of the learning process." The teacher, having rhetorical creative interaction skills, is able to overcome thesaurus, contra-suggestive, evaluative and interactional barriers in pedagogical communication [7].

The third, top level of the system is a teacher's communicative competence - their facilitation and "gobetween" skills. The teacher-facilitator, according to the metaphorical definition of C. Rogers, "trusts" in the developmental abilities of students. It is in a research situation where both teacher and student become subjects of the learning process, co-searchers of true knowledge, which dramatically changes their communicative roles and modifies the core meaning of the communicative leadership of the teacher. "The facilitator of learning gives priority to the students: What do you find interesting? What do you care about? What kinds of problems would like to know how to solve? And only after that they ask themselves: How can I help my students find proper informational resources? How can I help them evaluate their achievements and set new learning goals based on this self-evaluation?" [8]

The core of the teacher-facilitator' communicative personality is their disengagement and openness in communication, self-development and self-improvement abilities, empathy, trust in students, developed infusion and contagion mechanisms, and reflective skills.

It is necessary to define how facilitation is relevant to traditional pedagogical communication styles.

Facilitation is obviously opposed to ineffective communicative styles (authoritarian, communicationdistance and communication-intimidation) as far as a true teacher-facilitator should accept a sincere and friendly attitude to students, empathic understanding, and trust in the students. However, this does not mean that facilitating is similar to pandering, as the teacher is not trying to gain false credibility. Their goal is to form a personality that will be able to exist and function in a constantly changing world [9].

Facilitation is much more similar to effective pedagogical communication styles: democratic, based on enthusiasm for joint activities, and has a friendly disposition, as one of its main points is to accept the student and be truly interested in the learning process.

However, facilitation is different from other effective communicative styles. According to C. Roger's idea, the teacher is supposed to motivate their students to learn and give them the "freedom to learn", which is mostly conditioned by the refusal to have control and power over students, where they have freedom and personal responsibility. Providing the freedom to learn is directly connected with the trust relationship between teacher and students: "If I do not trust a human being, then I have to give them the information I selected so that they 
would not take their own, incorrect path. But if I trust the individual's ability to fulfil their own potential, then I can provide them with numerous opportunities and let them choose their own way, their own learning path" [8]. Moreover, as C. Rogers highlights, the facilitator does not fulfil the functions of a teacher, as they are only "motivators" [8].

Communication based on enthusiasm for joint activities and a friendly disposition assumes, of course, the teacher's desire to get their students interested and use problem-based learning. However, the teacher does not lose the role of an educator, and, consequently, does not provide their students with the freedom to learn, which is given in facilitation. A facilitator's aim is to "free curiosity and let people choose new directions according to their own interests," [8] - this is the main difference between facilitation and other pedagogical communication styles.

Thus, facilitation goes further than democratic communication styles in its trust and respect for learners, giving them the freedom of choice and an opportunity to be independent in the problem-solving process.

Psycho-pedagogical literature defines the personal competencies that each teacher-facilitator should have: the ability to define the values of their own pedagogical activity, build reflective practice, disconnect from their own interests and become more child-oriented, and plan pedagogical support stages keeping in mind the specific situation of every child, as well as the abilities that all members of the learning process have [10].

It must be emphasised that facilitation as a condition for the best pedagogical communication, first defined and developed in foreign pedagogics, is organically inherent in the Russian mental and speech consciousness and in the national insight about ideal leader (let us remember, for example, how Kutuzov (a famous Russian commander) is depicted as a military leader in the "War and Peace" by Leo Tolstoy).

Let us consider the example of the facilitation principle in teacher-learner interactions in the educational process of the modern school. Municipal general education institution in Rostov-on-Don, gymnasium No. 118 , is an example of a special culturaleducational milieu. The purpose of learning there is to make students sociable, open to communication, creative and strong-minded individuals who gain success by means of conflict-free methods, knowing how to build an individual development strategy. "Learning is becoming an inner need for our students, and creative reconsideration of the reality is their main goal", stated the school's principal in his public report.

The educational milieu in this gymnasium was created based on a special approach to lesson planning. All lessons in the gymnasium implement a learnercentred approach to education and "non-standard" (according to teachers and administration terminology) management of teacher-learner interaction.

It's important to stress that the administration of the grammar school pays much attention to learning space management so that it can stimulate development of the communicative space. Thus, each classroom traditionally equipped for the classroom educational system has a small room with a stage and spectator seating attached to it. The learners use this space to fulfil the roles of both speakers and listeners. This room is used for both extracurricular activities and traditional lessons.

Principles of learning process management, basic technologies, learning methods and forms implemented at gymnasium No. 118 (learner-centred education technologies; module, project and problem-based learning; information and communication technologies, meta-subject and integrative lessons as a meaning production environment; problem and educational workshops, conferences, workshops for teachers, various contests, conferences for students, a press-centre, a children's theatre, a "diplomat school", on-site internet communication on educational subjects, themed gatherings for parents, etc.) stimulate the subjectivity of its learners, as well as their cultural and intellectual potential and communicative culture.

Case technology can be considered an effective education technology that conforms to facilitation principles. A case represents the description of a real, concrete situation designed for students to learn how to analyse different types of information, its generalisation, and the formulation of problems and the development of possible solutions according to set criteria. This technology allows students to become a decision-making person; it develops a number of skills including analytical, practical, creative, communicative, social and self-evaluation skills.

A case should be well structured to be easy and comfortable to work with and should contain a foreword, a main part and an afterword.

The foreword may consist of a certain challenge: a short intriguing introduction, resume, basic research data, a glossary, key moments, questions for research, etc.

The main part includes the context: meaningful data on exterior factors that help to understand and interpret the case, a description of a peculiar situation connected with the major research question, and facts (statistics, documents extracts, questionnaire results, expert opinions, pictures, etc.)

The final part of the case, the afterword, contains additional information that will allow students to make sense of the case. It is possible to place information in the form of a database, appendices, links, reference lists, and contact lists.

Having an exciting introduction, clarity, proper examples and real life illustrations can make a case more interesting.

"Case-study technology is advantageous in its opportunities for group work in a common environment, usage of structured information that reduces possible uncertainty under the condition of limited time, usage of problem-based learning principles, and serves as an opportunity for students to gain a profound understanding of theoretical concepts, as well as basic knowledge, as well as the opportunity to build new effective activity models and develop basic synthesis skills.

Case work also develops debate skills and improves communicative skills [11]. A teacher's ability to form a 
proper case demonstrates the formation of a teacher's abilities to carry out their own version of pedagogical activity, design steps of pedagogical support, etc. Thus, teachers fulfil the facilitative student-teacher interaction principle in an educational process.

Here below is a brief description of the "Working with borrowed words and terminology" case planning.

One of the learning activity types in elementary and middle school is the spelling of lexicalized words. The learners usually make mistakes when spelling such words, failing to understand why this word is spelled this particular way. Almost $70 \%$ of lexicalized words are borrowed words (from English, German, French, Greek, and Italian). Teachers of various subjects face a similar problem - false spelling and/or incorrect definition of a word. For example, when a student misspells the word "sacrilegious", by spelling it "sacreligious", because they connect this term to be relevant to a "religious" topic (the spellings of these words swap the positions of the letters " $i$ " and "e", that is: "religious" vs. "sacrilegious"). Additionally, it is often the case that learners fail to see the difference between such words as emigrant and immigrant.

In order to plan a case and define possible difficulties that learners might face, it is necessary to answer the following questions:

1. What kind of skills do learners lack if they provide this kind of word definition?

2. What kind of lessons should be used to form and improve these skills?

3. What methods can be used to make spelling and pronunciation rules easier to remember?

4. What informational resources can be recommended to learners?

How (and at what stage) can we use tasks like: "Evaluate another version of a problem's solution, represented in a cartoon TV series where heroes solve spelling problems"; "Make a profile page for the author of a dictionary on a social network"; "Create a book trailer for one of the dictionaries."
The Russian school experience in the modern educational space already contains a large amount of pedagogical innovations. The reasonability of their usage is conditioned by the existing traditions in general education institutions, peculiarities of the personality of learners, and is mostly dependent on material and the technical basis of a given institution. However, the most important point, as we see it, is the personal and professional characteristics of a teacher, which define the choice of the "teacher-learner" paradigm that corresponds to tasks in the modern educational space.

\section{References}

1. S.V. Olefir, FR, 8 (2013) [In Rus]

2. V.A. Kan-Kalik, To the Teacher: on Pedagogical Communication (1987) [In Rus]

3. A.K. Mikhalskaya, Pedagogical Rhetoric (2013) [In Rus]

4. A.A. Leontiev, Pedagogical Communication (1996) [In Rus]

5. E.L. Erokhina, SJE, 3 (2013) [In Rus]

6. S.E. Tikhonov, Rhetoric, Rhetoric and Communication in School: Understanding and Implementing During the Time of Educational Modernisation (2005) [In Rus]

7. A.A. Murashov, Teacher-Learner Creative Interaction: Providing Rhetoric (1999) [In Rus]

8. C.Rogers, and J. Freiberg, Freedom to Learn (2002)

9. E.L. Erokhina, Facilitation in the System of Pedagogical Communication Styles (2014) [In Rus]

10. N.N. Mikhailova, NE, 6 (1998) [In Rus]

11. I.N. Dobrotina, Modern Lesson Models of the Russian Language in Grades 5-9 (2014) [In Rus] 